\title{
Pharmacokinetics/pharmacodynamics of marbofloxacin in a Pasteurella multocida serious murine lung infection model
}

\author{
Ying $\mathrm{Qu}^{\dagger}$, Zhenzhen $\mathrm{Qiu}^{\dagger}$, Changfu Cao, Yan Lu, Meizhen Sun, Chaoping Liang and Zhenling Zeng*
}

\begin{abstract}
Background: Marbofloxacin is a third-generation fluoroquinolone developed solely for veterinary medicine with a broad spectrum of antibacterial activity against some Gram-positive and most Gram-negative bacteria, including the bovine respiratory tract pathogen, Pasteurella multocida. The objective of our study was to elucidate the pharmacokinetics and pharmacodynamics of marbofloxacin in a Pasteurella multocida infected murine lung model, and to estimate the magnitudes of pharmacokinetics-pharmacodynamics parameters associated with various effects.

Results: The pharmacokinetic studies revealed marbofloxacin kinetics in infected mice were linear over a dose ranging from 1.25 to $10 \mathrm{mg} / \mathrm{kg}$ of body weight. The protein binding in the plasma of neutropenic infected mice was $29.77 \%$. The magnitudes of the ratio of the free-drug area under the concentration-time curve over $24 \mathrm{~h}$ to MIC ( $\left.f A \cup \mathrm{C}_{0-24 \mathrm{~h}} / \mathrm{MIC}\right)$ associated with static effect, a $2 \log _{10}$ reduction and a $3 \log _{10}$ reduction of bacterial counts were 40.84, 139.34, and 278.08 h, respectively.

Conclusions: Based on the dose range study, marbofloxacin exhibited concentration-dependent killing and the fAUC/ MIC was the PK/PD index that correlated best with efficacy $\left(R^{2}=83 \%\right)$. On the basis of a bactericidal effect goal of $f A \cup C_{0-24 h} / \mathrm{MIC}$ of $278.08 \mathrm{~h}$, if marbofloxacin is used for the treatment of $P$. multocida serious lung infection with an $\mathrm{MIC}_{90}$ of $0.12 \mathrm{\mu g} / \mathrm{ml}$, the current dose $(2 \mathrm{mg} / \mathrm{kg}$ ) would fail to achieve a bactericidal effect. It would benefit from higher doses $(4 \sim 6 \mathrm{mg} / \mathrm{kg}$ ) than those commonly used in clinical practice.
\end{abstract}

Keywords: Marbofloxacin, Pharmacokinetics/Pharmacodynamics, Pasteurella multocida, Mouse-lung model

\section{Background}

Pasteurella multocida is a pathogenic Gram-negative bacterium that is a common inhabitant of the upper respiratory tract of calves [1]. It may cause a wide spectrum of diseases ranging from septicemia to pneumonia [2]. Marbofloxacin, a synthetic third-generation fluoroquinolone has been developed solely for veterinary use and displays a broad spectrum of antimicrobial activity against most Gram-negative and some Gram-positive bacteria [3-5]. It has been approved for the treatment of respiratory, urinary tract, soft tissue and dermatological infections in cattle, pigs, dogs, and cats [6-8].

\footnotetext{
* Correspondence: zlzeng@scau.edu.cn

${ }^{\dagger}$ Equal contributors

National Reference Laboratory of Veterinary Drug Residues (SCAU), College of Veterinary Medicine, South China Agriculture University, Guangzhou, China
}

Using pharmacokinetics and pharmacodynamics (PK-PD) principles is a widely accepted approach for optimization of antimicrobial therapy $[9,10]$. Three principal PK-PD surrogate markers of efficacy $\left(\mathrm{AUC}_{0 \rightarrow 24 \mathrm{~h}} / \mathrm{MIC}, \mathrm{C}_{\max } /\right.$ MIC, $\mathrm{T}_{>\mathrm{MIC}}$ ) have been used as a basis for dose optimization by quantifying the potency and efficacy of antimicrobials against target pathogens $[11,12]$.

Previous studies have demonstrated that marbofloxacin displays a concentration-dependent killing mechanism of action and the $\mathrm{AUC}_{24 \mathrm{~h}} / \mathrm{MIC}$ surrogate marker is the PK-PD parameter best linked with efficacy [3, 13, 14]. There are numerous studies describing the characteristics of the time-kill profiles and growth inhibition of marbofloxacin against $P$. multocida. However, the pharmacodynamic properties of marbofloxacin were elucidated by using in vitro dynamic models or ex vivo using calf serum, exudate, and transudate harvested from a tissue cage 
model. The results were established by modelling in vitro time-kill data with pharmacokinetic properties of marbofloxacin. The goal of our studies was to characterize the in vivo activity of marbofloxacin in a mouse model of serious $P$. multocida infection, and to determine the magnitude of PK/PD parameter predictive of efficacy. Today, animal pharmacokinetic-pharmacodynamic (PK-PD) infection models serve as a cornerstone of the preclinical assessment process for antibacterial agents. The magnitude of exposure identified for bacterial stasis in immunocompromised animals was similar to the exposure threshold associated with good clinical outcomes for patients treated with oritavancin or linezolid for bacteremia [15]. A neutropenic mouse model is always used in human medicine research [16]. We can exclude the host defense and only analyze the effects of drug on bacteria with this model, which is known to be relevant for drawing conclusions about drug PK/PD with humans $[16,17]$.

\section{Methods}

\section{Bacteria and antibiotic}

P. multocida strain CVCC 411, isolated from a buffalo that died from hemorrhagic septicemia, was obtained from National Veterinary Microorganism Strains Preservation Management Centre (Beijing, China). Marbofloxacin was a $10 \%$ injectable aqueous solution obtained from Veterinary Pharmaceutical Corporation (Yuanzhen Co., Ltd, Hebei, China). Marbofloxacin reference standard was purchased from Dr. Ehenstorfer GmbH company (Germany) and ofloxacin was aquired from the National Institute for Food and Drug Control (Beijing, China).

\section{In vitro susceptibility testing}

The MIC of marbofloxcin was determined by broth microdilution methodology according to the Clinical and Laboratory Standards Institute (CLSI) recommended methods and quality control requirements. Susceptibility testing was performed in triplicates.

\section{Inoculum preparation}

A few colonies of freshly grown P. multocida CVCC 411 from Tryptic Soy agar (Guangdong Huankai Microbial Sci. \& Tech. Co., Ltd., Guangzhou, China) plates supplemented with $5 \%$ sheep blood (Puboxin Biotechnology Co., Ltd., Beijing, China) were cultured in Mueller-Hinton II broth (Becton Dickinson, Sparks, MD, USA) with shaking at $200 \mathrm{rpm}$ at $37^{\circ} \mathrm{C}$ for $10 \mathrm{~h}$ (final cell count approximately $10^{9} \mathrm{CFU} / \mathrm{mL}$ ). Bacteria were collected by centrifugation at $3,000 \mathrm{~g}$ for $10 \mathrm{~min}$ and re-suspended in $0.9 \% \mathrm{NaCl}$ to obtain a final suspension containing $10^{10} \mathrm{CFU} / \mathrm{mL}$. This suspension was then diluted 100 times to obtain a bacterial concentration at $10^{8} \mathrm{CFU} / \mathrm{mL}$.

\section{Animals}

Six-week-old, specific-pathogen-free, female ICR mice (Medical Experimental Animal Center of Guangdong Province, Guangzhou, China) weighing between 22 and $24 \mathrm{~g}$ were used for the experiments. All animal studies were approved by the Animal Research Committees of South China Agriculture University. The animals were maintained in accordance with the American Association for Accreditation of Laboratory Animal Care criteria. All sections of this report adhere to the ARRIVE Guidelines for reporting animal research. A completed ARRIVE guidelines checklist is included in Additional file 1.

\section{Neutropenic mouse lung infection model}

Before the mice were infected with P.multocida using endotracheal intubation, the mice were rendered neutropenic by injecting cyclophosphamide (Aladdin Co., Ltd., Shanghai, China) intraperitoneally 4 days $(150 \mathrm{mg} / \mathrm{kg}$ of body weight) and 1 day (100 $\mathrm{mg} / \mathrm{kg}$ of body weight) [18]. On the 6th day, the mice were anesthetized by injecting $1 \%$ pentobarbital sodium (XiangBo Biotechnology Co., Ltd., Guangdong, China) solution $(50 \mathrm{mg} / \mathrm{kg}$ ) intraperitoneally. A simple 22G "Y" type intravenous catheter (PUYI Medical Devices Co., Ltd., Shanghai, China) that consisted of an IV catheter connected to a PVC flexible pipe was used to intubate the mice. A $50 \mu \mathrm{L}$ saline suspension of P. multocida CVCC411 containing $10^{8} \mathrm{CFU} / \mathrm{mL}$ described above was injected into the PVC flexible pipe and then kept horizontal. The anesthetized mouse was placed on an adjustable-angled support suspended by its upper incisors; the tongue was gently pulled out of the mouth. Using a light source illuminating the neck of the mouse, we can clearly observe the glottis opening and then closing alternately. The catheter was inserted through the glottis and if the catheter was successfully inserted into the trachea, the inoculum in the PVC flexible pipe would fluctuate following the breath of the mouse. We used $0.8 \mathrm{~mL}$ gas to thrust the $50 \mu \mathrm{L}$ bacterial inoculum into the lung (this process operated approximately for $2 \mathrm{~s}$ ), thereafter, mouse was held in a vertical position for $15 \mathrm{~s}$. Antimicrobial therapy was initiated $10 \mathrm{~h}$ when the mice showed lethargy and dyspnea after the infection of $P$. multocida.

\section{PK studies}

The neutropenic mice were infected with $P$. multocida as described above, and $10 \mathrm{~h}$ later were administered with single subcutaneous doses of $1.25,2.5,5$, or $10 \mathrm{mg} / \mathrm{kg}$ marbofloxacin in $0.2 \mathrm{~mL}$ volumes. Groups of four mice were each sampled by retro-orbital puncture at 0.083 , $0.25,0.5,0.75,1,2,4,6,8,12$ and $24 \mathrm{~h}$ after dosing. The total volume collected from each individual mouse was less than $10 \%$ of the total blood volume, namely each mouse was sampled about three times and each time a blood sample of approximately $0.25 \mathrm{~mL}$ was obtained. 
Blood samples were centrifuged at 7,000 g for $10 \mathrm{~min}$ at $4{ }^{\circ} \mathrm{C}$, the plasma were removed and stored at $-20{ }^{\circ} \mathrm{C}$ until the assay. Marbofloxacin concentrations were determined using a HPLC method with fluorescence detection (excitation and emission wavelengths were $295 \mathrm{~nm}$ and $500 \mathrm{~nm}$ ). Briefly, marbofloxacin was extracted as follows: $0.1 \mathrm{~mL}$ plasma, spiked with $10 \mu \mathrm{L}$ internal standard-ofloxacin, was added to $3 \mathrm{~mL}$ of trichloromethane and vortexed for 30s. The organic layer was collected after centrifugation for $10 \mathrm{~min}$ at 3,000 $\mathrm{g}$, and then concentrated to dryness under a stream of nitrogen. A $0.2 \mathrm{~mL}$ mobile phase was used to re-suspend the dried sample and a $20 \mu \mathrm{L}$ aliquot was taken and injected into HPLC for analysis. The standard calibration curve of marbofloxacin was linear for concentrations ranging from 0.01 to $5 \mu \mathrm{g} / \mathrm{mL}$. The intraday and inter-day precision levels varied from $4.13 \%$ to $7.18 \%$ and from $6.70 \%$ to $8.24 \%$, respectively. The protein binding in the plasma of neutropenic infected mice was determined by ultrafiltration methods. The level of binding was measured with marbofloxacin concentrations of $0.05,0.5$ and $5 \mu \mathrm{g} / \mathrm{mL}$.

\section{PD parameter determination}

The neutropenic mice were infected with $P$. multocida using endotracheal intubation as previously described; we used twenty control mice which were not treated to assess the growth of $P$. multocida in the lungs. Groups of five mice were sacrificed 2, 5, 10 and $24 \mathrm{~h}$ after the inoculation and the amount of bacteria in the lungs was counted. The neutropenic mice were infected with $P$. multocida $10 \mathrm{~h}$ prior to the start of therapy. Groups of five mice were treated for $24 \mathrm{~h}$ with single marbofloxacin doses from 0.625 to $10 \mathrm{mg} / \mathrm{kg} / 24 \mathrm{~h}(0.625,1,1.25,2,2.5$, $4,5,8,10 \mathrm{mg} / \mathrm{kg}$ ). The drug was administered subcutaneously in $0.2 \mathrm{ml}$ volumes. The treated mice were humanely killed $24 \mathrm{~h}$ after initiation of treatment; the lungs were aseptically removed and homogenized in $5 \mathrm{~mL}$ of sterilized saline, individually. Bacterial counts of each lung were determined by serial 10 -fold dilutions of homogenates, $20 \mu \mathrm{L}$ drops of the successive dilutions were dropped in triplicate on a TSA (supplemented with $5 \%$ sheep blood) surface and waited to dry before incubating at $37^{\circ} \mathrm{C}$. If the bacterial counts were less than $250 \mathrm{CFU} / \mathrm{lung}, 100 \mu \mathrm{L}$ of the homogenates were plated in triplicate on agar. The lowest level of detection was $50 \mathrm{CFU} / \mathrm{lung}$ (equivalent to one colony per plate). The untreated control mice were humanely killed just before treatment and after $24 \mathrm{~h}$.

\section{PK and PK/PD analysis}

The data obtained with a single subcutaneous injection of $1.25,2.5,5$ and $10 \mathrm{mg} / \mathrm{kg}$ marbofloxacin were analyzed separately using WinNonlin version 5.2 (Pharsight Corporation). Marbofloxacin concentration-time data were best described using the noncompartment model with extravascular input. According to dose proportionality from the obtained PK parameters, we used them to estimate the $\mathrm{AUC}_{0-24 \mathrm{~h}}, \mathrm{C}_{\max }$ for each tested mabofloxacin dosing for which no kinetics were determined. The PK/PD analysis was performed by using the inhibitory effect $E_{\max }$ model. This model is described by the following equation: $\mathrm{E}=\mathrm{E}_{\max }-\left(\mathrm{E}_{\max }-\mathrm{E}_{0}\right) *\left(\mathrm{C} /\left(\mathrm{EC}_{50}+\mathrm{C}\right)\right)$, where $\mathrm{E}$ is the change in $\log _{10} \mathrm{CFU} / \mathrm{lung}$ after $24 \mathrm{~h}$ in treated mice compared to the initial $\log _{10} \mathrm{CFU} / \mathrm{lung}$ in untreated control mice; $\mathrm{E}_{\max }$ is the log change in CFU per lung, comparing 0 and $24 \mathrm{~h}$ in the untreated control mice; $\mathrm{E}_{0}$ is the change in $\log _{10} \mathrm{CFU} /$ lung between the treated mice with untreated mice after the $24 \mathrm{~h}$ period of the study, when the detection limit is reached; $C$ is the PK/PD parameter (e.g. $f \mathrm{AUC} / \mathrm{MIC}, f \mathrm{Cmax} / \mathrm{MIC}, f \mathrm{~T}_{>\mathrm{MIC}}$ ); $\mathrm{EC}_{50}$ is the $C$ value at which $50 \%$ of the maximal antibacterial effect is produced. These PD parameters were calculated using the nonlinear regression program (WinNonlin, Pharsight Corporation).

\section{Results}

In vitro susceptibility testing

The MIC of marbofloxacin for P. multocia CVCC 411 was $0.031 \mu \mathrm{g} / \mathrm{mL}$ by the broth microdilution methodology.

\section{Pharmacokinetic study}

The time-concentration curves of marbofloxacin in the plasma of infected neutropenic mice after single subcutaneous doses of $1.25,2.5,5$, and $10 \mathrm{mg} / \mathrm{kg}$ are shown in Fig. 1. The PK data obtained with different marbofloxacin doses were analyzed using a noncompartment model with extravascular input, and the obtained values of marbofloxacin pharmacokinetic parameters are shown in Table 1. The PK parameters were dose-dependent, where the AUC/dose values for the escalating single doses ranged from 2.29 to 2.41 , and the $C_{\max } /$ dose values ranged from 0.43 to 0.53 . The plasma protein binding of marbofloxacin at concentrations of $0.05,0.5,5 \mu \mathrm{g} / \mathrm{ml}$ were $33.04 \pm 2.37 \%, 25.70 \pm 1.18 \%, 30.55 \pm 0.10 \%$. And the mean value of $29.77 \%$ of the plasma protein binding was used to calculate the free plasma concentrations. Thus, we can obtain the free PK parameter values.

\section{Lung infection model}

The intubation method in this study was based on other endotracheal intubation methods [19] and improved by using a 22G "Y" type intravenous catheter. This method features well in terms of repeatability, and it is noninvasive, inexpensive and rapid. About $6.81 \log _{10} \mathrm{CFU} /$ mouse was inoculated via the trachea, but by two hours after the inoculation, the bacterial load in mice was $6.15 \pm 0.21 \log _{10} \mathrm{CFU} / \mathrm{lung}$. Five hours after inoculation the bacterial burden was $6.60 \pm 0.15 \log _{10} \mathrm{CFU} / \mathrm{lung}$ and the mice had no clinical signs of infection. Ten hours 


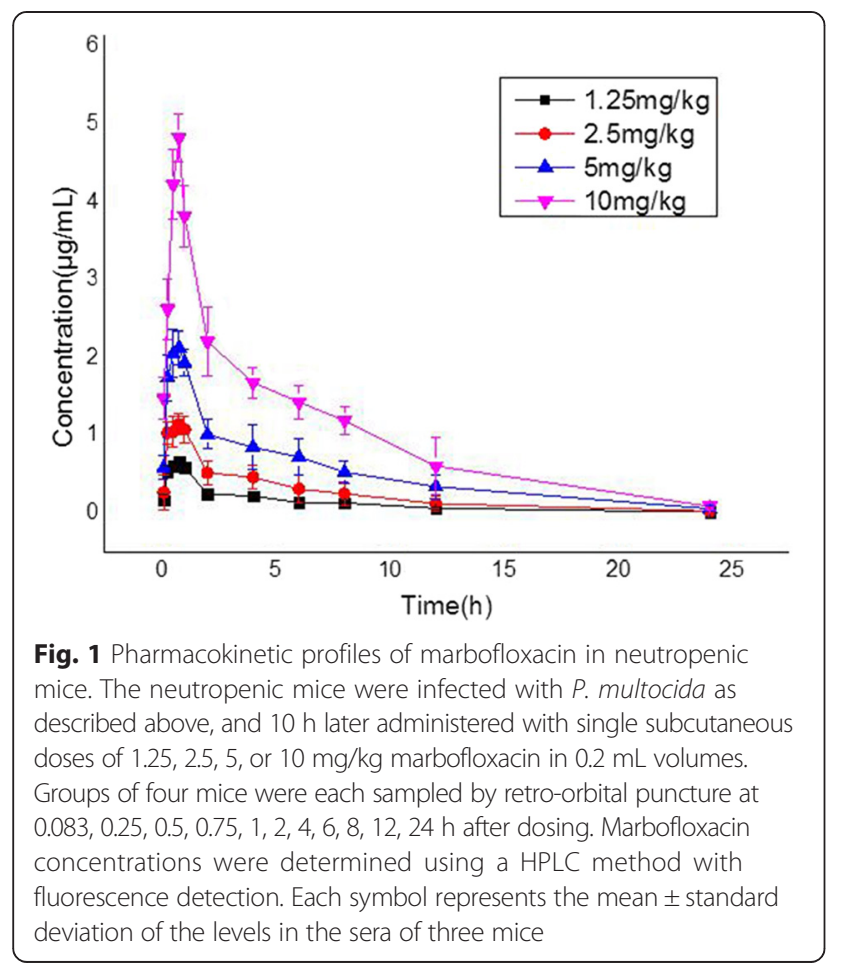

after the inoculation, the mice were lethargic with dyspnea and the bacterial population reached $7.38 \pm 0.19 \log _{10}$ $\mathrm{CFU} / \mathrm{lung}$, and by $24 \mathrm{~h}$ after inoculation, the bacterial population increased to $8.82 \pm 0.16 \log _{10} \mathrm{CFU} / \mathrm{lung}$, and the mice were on the verge of death.

\section{PK/PD analysis}

(i) Total bacterial populations. Total bacterial populations after $24 \mathrm{~h}$ of marbofloxacin treatment are reported in Table 2. At the start of therapy, mice were infected with $7.12 \pm 0.12 \log _{10}$ CFU/lung of P. multocia CVCC 411. The untreated control mice died in around $24 \mathrm{~h}$ post-challenge and the organisms grew $1.95 \pm 0.19 \log _{10}$ $\mathrm{CFU} /$ lung. The relationships between efficacy and each of the PK/PD indices $\left(f \mathrm{AUC}_{0-24 \mathrm{~h}} / \mathrm{MIC}, f \mathrm{Cmax} / \mathrm{MIC}\right)$ are

Table 1 Pharmacokinetic parameters obtained from plasma concentrations after administration of marbofloxacin in infected neutropenic mice

\begin{tabular}{llcccc}
\hline $\begin{array}{l}\text { Marbofloxacin } \\
\text { dose }(\mathrm{mg} / \mathrm{kg})\end{array}$ & $\begin{array}{l}\mathrm{C}_{\max } \\
\text { mean } \pm \mathrm{SD} \\
(\mu \mathrm{g} / \mathrm{ml})\end{array}$ & $\mathrm{T}_{\max }(\mathrm{h})$ & $\begin{array}{l}\mathrm{AUC} \\
(\mu \mathrm{g} . \mathrm{h} / \mathrm{ml})\end{array}$ & $\begin{array}{l}\mathrm{Cl} \\
\left(\mathrm{ml} \mathrm{kg}^{-1} \mathrm{~h}^{-1}\right)\end{array}$ & $\mathrm{T}_{1 / 2}(\mathrm{~h})$ \\
\hline 1.25 & $0.66 \pm 0.07$ & 0.75 & 2.92 & 411.2 & 5.40 \\
2.5 & $1.14 \pm 0.14$ & 0.75 & 5.73 & 420.3 & 5.23 \\
5 & $2.13 \pm 0.22$ & 0.75 & 12.05 & 400.9 & 5.00 \\
10 & $4.83 \pm 0.30$ & 0.75 & 23.90 & 408.9 & 4.29 \\
\hline
\end{tabular}

$\mathrm{C}_{\text {max }}$ : maximum concentration of drug in plasma

$\mathrm{T}_{\max }$ : time to maximum concentration of drug in plasma

AUC: area under the concentration-time curve

$\mathrm{Cl}$ : clearance

$\mathrm{T}_{1 / 2}$ : half-life
Table 2 Total bacterial populations after 24-h exposure to different doses of marbofloxacin

\begin{tabular}{|c|c|c|}
\hline $\begin{array}{l}\text { Treatment group } \\
\text { and time point }\end{array}$ & $\begin{array}{l}\text { Total dose } \\
(\mathrm{mg} / \mathrm{kg})\end{array}$ & $\begin{array}{l}\text { Bacterial population (mean } \pm \text { SD) } \\
\text { ( } \log _{10} \mathrm{CFU/lung)}\end{array}$ \\
\hline Untreated controls & 0 & \\
\hline At start of treatment ${ }^{a}$ & & $7.12 \pm 0.12$ \\
\hline $24 \mathrm{~h}$ after inoculation ${ }^{\mathrm{b}}$ & & $9.07 \pm 0.19$ \\
\hline $\begin{array}{l}24 \mathrm{~h} \text { after start of } \\
\text { treatment }\end{array}$ & & $* *$ \\
\hline \multirow[t]{9}{*}{ Single administration } & 0.625 & $7.79 \pm 0.56$ \\
\hline & 1 & $6.87 \pm 0.91$ \\
\hline & 1.25 & $6.31 \pm 0.74$ \\
\hline & 2 & $5.20 \pm 0.74$ \\
\hline & 2.5 & $4.97 \pm 0.52$ \\
\hline & 4 & $4.88 \pm 0.41$ \\
\hline & 5 & $4.14 \pm 0.49$ \\
\hline & 8 & $3.64 \pm 0.63$ \\
\hline & 10 & $3.40 \pm 0.32$ \\
\hline
\end{tabular}

${ }^{\mathrm{a}}$ Total bacterial population $10 \mathrm{~h}$ after the time of infection

${ }^{b} 24 \mathrm{~h}$ after the inoculation was the time that the mice approached to death, and the lungs were removed for calculation the bacterial population **The mice were already dead

shown in Fig. 2. $f \mathrm{AUC}_{0-24 \mathrm{~h}} / \mathrm{MIC}$ correlated well with microbiological efficacy $\left(\mathrm{R}^{2}=0.83\right)$, and a similar relationship was observed for the fCmax/MIC correlated with efficacy $\left(R^{2}=0.82\right)$. (ii) $P K / P D$ parameters determining efficacy: The dose-response relationships with single doses of marbofloxacin for $P$. multocia were evaluated using inhibitory Effect $E_{\max }$ model. The PK/PD model parameter estimates for the $f \mathrm{AUC}_{0-24 \mathrm{~h}} / \mathrm{MIC}$ index and the values of $f \mathrm{AUC}_{0-24 \mathrm{~h}} / \mathrm{MIC}$ required for static effect, 2 and $3 \log _{10}$ reduction of bacterial burden are shown in Table 3. The highest dose of $10 \mathrm{mg} / \mathrm{kg}$ marbofloxacin, corresponding to $f \mathrm{AUC}_{0-24 \mathrm{~h}} / \mathrm{MIC}$ values of $537.12 \mathrm{~h}$, reduced the bacterial burden by more than 3 log. The $f \mathrm{AUC}_{0-24 \mathrm{~h}} / \mathrm{MIC}$ values of $91.08 \pm 16.49 \mathrm{~h}$, equivalent to $1.77 \pm 0.32 \mathrm{mg} / \mathrm{kg}$ for marbofloxacin, performed $50 \%$ of the maximum antibacterial effect.

\section{Discussion}

In the current study, we used a neutropenic mouse-lung model to characterize the PD profiles of marbofloxacin, a fluoroquinolone of veterinary interest. We infected the mice with $P$. multocida, which eventually led to the development of septicemia, This murine lung infection model was also used to elucidate the magnitude of the $f \mathrm{AUC}_{0-24 \mathrm{~h}} / \mathrm{MIC}$ index required for various effects.

Previous in vitro and in vivo studies demonstrated that inoculum size influenced the pharmacodynamics of antimicrobial drugs. Indeed, the different inoculum sizes were directly inoculated into broth and animals but the natural growth of the bacterial was not taken into 

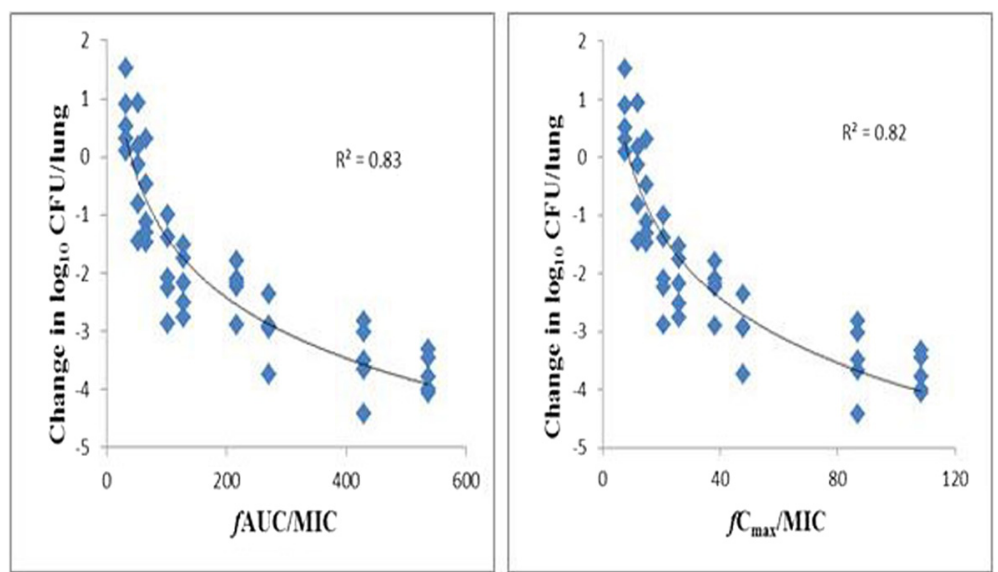

Fig. 2 Relationships between marbofloxacin's $f A \cup C_{24} / M I C, f C$ max $/ M I C$ and microbiological efficacy for pasteurella multocida. The neutropenic mice were infected with $P$. multocida $10 \mathrm{~h}$ prior to the start of therapy. Groups of five mice were treated for $24 \mathrm{~h}$ with single marbofloxacin doses from 0.625 to $10 \mathrm{mg} / \mathrm{kg} / 24 \mathrm{~h}(0.625,1,1.25,2,2.5,4,5,8,10 \mathrm{mg} / \mathrm{kg})$. After $24 \mathrm{~h}$ of therapy, the amount of bacteria in the lungs was counted. The figure above reveals the relationships of marbofloxacin's $f A \cup C_{24} / \mathrm{MIC}$ and $\mathrm{CC}_{\max } / \mathrm{MIC}$ for pasteurella multocida CVCC 411 with the change in the $\log _{10}$ number of CFU/lung after $24 \mathrm{~h}$ of therapy. Each symbol represents a single lung tissue per mouse. $\mathrm{R}^{2}$ is the correlation coefficient

account in these studies [20,21]. In the present study, when the mice had slight clinical signs, we administered marbofloxacin at this time to mimic "conventional" curative treatment. In an earlier study, Ferran et al. [22] referred to the later "conventional" curative treatment in a mouse-lung model of $P$. multocida infection studies.

Previous in vivo studies had shown that bacterial infections altered the PK of drugs, including fluoroquinolone antimicrobials, such as marbofloxacin [16, 21, 23, 24]. We evaluated the PK of marbofloxacin in P. multocidainfected mice with single subcutaneous doses of 1.25 , $2.5,5,10 \mathrm{mg} / \mathrm{kg}$. The PK data in Table 2 showed doseproportionality for marbofloxacin in P.multocida infected mice, with the AUC and $\mathrm{C}_{\max }$ proportional to the dose. This dose-proportionality was also previously demonstrated in mice infected with Escherichia coli in the thighs [20]. In this study, the AUC value of marbofloxacin in mice receiving $10 \mathrm{mg} / \mathrm{kg}$ was $23.90 \mu \mathrm{g} . \mathrm{h} / \mathrm{ml}$, which was in accordance with the AUC values of the mice

Table 3 The PK/PD parameter estimates for the fAUC/MIC index and the $F A U C / M I C$ required for various antibacterial effects

\begin{tabular}{lll}
\hline Parameter & Unit & Mean \pm SD \\
\hline$E_{\max }$ & $\log _{10}$ CFU/lung & $2.08 \pm 0.26$ \\
$\mathrm{E}_{0}$ & $\log _{10} \mathrm{CFU} / \mathrm{lung}$ & $-4.67 \pm 0.32$ \\
fAUC/MIC for $\mathrm{EC}_{50}$ & $\mathrm{~h}$ & $91.08 \pm 16.49$ \\
fAUC/MIC for static effect & $\mathrm{h}$ & 40.84 \\
fAUC/MIC for $1 \log _{10}$ kill & $\mathrm{h}$ & 76.88 \\
fAUC/MIC for $2 \log _{10}$ kill & $\mathrm{h}$ & 139.34 \\
fAUC/MIC for $3 \log _{10}$ kill & $\mathrm{h}$ & 278.08 \\
\hline
\end{tabular}

receiving $20 \mathrm{mg} / \mathrm{kg}$ marboflxacin for late administration after inoculation of $P$. multocida $(54 \mu \mathrm{g} . \mathrm{h} / \mathrm{ml})$ [22]. The clearance of $410.33 \pm 7.98 \mathrm{ml} \mathrm{kg}^{-1} \mathrm{~h}^{-1}$ of the four doses of marbofloxacin was similar to the clearance reported in the mice receiving $20 \mathrm{mg} / \mathrm{kg}$ marbofloxacin for late administration after inoculation of $P$. multocida $\left(370 \mathrm{ml} \mathrm{kg}^{-1} \mathrm{~h}^{-1}\right.$ ) [22]. The evolution of the disease induced a lower clearance of marbofloxacin, as previously observed [20]. The elimination half-life was $4.98 \pm 0.49 \mathrm{~h}$ for the four doses in infected mice, and the value was higher in this study than the previously reported values. The production of endotoxins by gram-negative bacterial was shown to decrease the activity of hepatic metabolism, the renal blood flow, and the glomerular filtration rate, and might be the explanation for the alteration of the drug elimination [20]. Both organisms are gram-negative so endotoxins could have played a role in both infections. Since single-injection cures are of major importance to the cattle industry, we only administered a single treatment within $24 \mathrm{~h}$ in this study, rather than the multiple dosing regimens generally employed in other in vivo studies.

Several animal infection models have identified that the fluoroquinolones display the characteristics of concentration-dependent killing and the AUC/MIC ratio is the PK/PD index most predictive of the antibacterial effect $[16,25]$. Based upon $\mathrm{R}^{2}$ values and visual examination of the fits, data from this lung infection model study confirmed that $f \mathrm{AUC}_{0-24 \mathrm{~h}} / \mathrm{MIC}$ and $f \mathrm{C}_{\max } / \mathrm{MIC}$ well correlated with efficacy of marbofloxacin against P. multocida. In the current investigation, the $f \mathrm{AUC}_{0-24 \mathrm{~h}} /$ MIC required to produce a static effect, $2 \log _{10}$ reduction and $3 \log _{10}$ reduction in bacterial counts against $P$. 
multocida were $40.84,139.34,278.08 \mathrm{~h}$, respectively, which were higher than observed in previous studies. Potter et al. [14] found that the mean $\mathrm{AUC}_{24 \mathrm{~h}} / \mathrm{MIC}$ values of marbofloxacin for no reduction, $3 \log _{10}$ and $4 \log _{10}$ reductions in bacterial count from the initial inoculum count, based on serum MICs, were 48.6, 64.9, and $74.8 \mathrm{~h}$ for $P$. multocida. Moreover, the corresponding values were $24.35,44.24$, and $64.36 \mathrm{~h}$ in the studies reported by Illambas et al. [13]. In this present study, the initial bacterial load (7.12 $\left.\pm 0.12 \log _{10} \mathrm{CFU} / \mathrm{lung}\right)$ was higher than a medium inoculum count of $5 * 10^{6} \mathrm{CFU} / \mathrm{ml}$ routinely used in time-kill studies. As previously observed, pathogen load impacts the drug concentration required for inhibition of growth, with a general expectation of a higher dosage requirement for higher pathogen loads [13]. Therefore, the higher initial P. multocida load in this murine lung infection model might explain the higher $f$ AUC/MIC values for various magnitudes of effect. Previous reports found that for a low and a high inoculum of bacterial in the mouse infection model, a low and a high value of $\mathrm{AUC}_{24} / \mathrm{MIC}$, respectively, were needed for bactericidal effect $[20,21]$. These findings fully confirmed that the inoculum size influenced the values of pharmacokinetic/pharmacodynamic indices.

\section{Conclusions}

The present study showed that $f A U C / M I C$ and $f C_{\max } /$ MIC well correlated with efficacy of marbofloxacin against $P$. multocida. The value of the $24 \mathrm{~h}$ static dose was a $f \mathrm{AUC}_{0-24 \mathrm{~h}} / \mathrm{MIC}$ of $40.84 \mathrm{~h}$ and when the ratio reached $91.08 \mathrm{~h}$, rates of microbiologic cure approached $50 \%$. Moreover, the results showed that a bactericidal action was not achieved until the $f \mathrm{AUC}_{0-24 \mathrm{~h}} / \mathrm{MIC}$ had reached $278.08 \mathrm{~h}$.

In conclusion, the antimicrobial PD in humans may be predicted from studies with animal models. According to the pharmacokinetic properties and the PK/PD parameters, the neutropenic mouse model has successfully predicted the dose of therapy in human medicine area $[16,17,25]$. Therefore, in this study, the recommended dose of marbofloxacin of $2 \mathrm{mg} / \mathrm{kg}$ for cattle against bovine respiratory disease produced a $24 \mathrm{~h}$ AUC of 10-15 $\mu \mathrm{g} . \mathrm{h} / \mathrm{ml}$ [5]. On the basis of a bactericidal effect goal of $f \mathrm{AUC}_{0-24 \mathrm{~h}} / \mathrm{MIC}$ of $278.08 \mathrm{~h}$, this model would predict that if marbofloxacin is used for the treatment of P. multocida serious lung infection with an $\mathrm{MIC}_{90}$ of $0.12 \mu \mathrm{g} / \mathrm{ml}$, the current dose would fail to achieve a bactericidal effect. It would benefit from higher doses $(4 \sim 6 \mathrm{mg} / \mathrm{kg})$ than those commonly used in clinical practice. However, with drugs from the fluoroquinolone class, the presence of neutrophils can enhance antimicrobial activity by up to a factor of four to six [26]. Thus the above dosage was a theoretical value, which should further validate in clinical or field study.

\section{Additional file}

Additional file 1: The ARRIVE Guidelines Checklist. Animal Research: Reporting In Vivo Experiments. (PDF 391 kb)

\section{Abbreviations}

P. multocida: Pasteurella multocida; MIC: minimum inhibitory concentration; PK: Pharmacokinetics; PD: Pharmacodynamics; AUC: area under the curve; $C_{\text {max }}$ : peak serum (or plasma) concentration; $f A \cup C_{24 h} / M I C:$ the ratio of area under the free plasma/serum concentration-time curve over $24 \mathrm{~h}$ to $\mathrm{MIC}$; $\mathrm{fC}_{\text {max }} / \mathrm{MIC}$ : the ratio of free peak serum (or plasma) concentration measured in vivo to MIC determined in vitro; CFU: Colony forming unit; CVCC: China veterinary culture collection; HPLC: high performance liquid chromatography; CLSI: clinical and laboratory standards institute.

\section{Competing interests}

The authors declare that they have no competing interests.

\section{Authors' contributions}

YQ and ZQ contributed equally to this study. YL; ZS; PL collected and analysis samples FC; $L Z$ and $Y Q$ analysis data. YQ and ZQ designed and conducted the experiment. YQ drafted the manuscript. All authors read and approved the final manuscript.

\section{Acknowledgements}

This work is supported financially by the National Natural Science Foundation of China (grant 31372480) and the National Key Basic Research Program of China (grant 2013CB127200).

Received: 21 April 2015 Accepted: 24 November 2015

Published online: 02 December 2015

\section{References}

1. Dabo SM, Taylor JD, Confer AW. Pasteurella multocida and bovine respiratory disease. Anim Health Res Rev. 2007;8(2):129-50.

2. Tabatabaei M, Liu Z, Finucane A, Parton R, Coote J. Protective Immunity Conferred by Attenuated aroA Derivatives of Pasteurella multocida B:2 Strains in a Mouse Model of Hemorrhagic Septicemia. Infect Immun. 2002;70(7):3355-62.

3. Shan Q, Wang J, Yang F, Ding H, Liang C, Lv Z, et al. Pharmacokinetic/ pharmacodynamic relationship of marbofloxacin against Pasteurella multocida in a tissue-cage model in yellow cattle. J Vet Pharmacol Ther. 2014;37(3):222-30.

4. Thomas A, Nicolas C, Dizier I, Mainil J, Linden A. Antibiotic susceptibilities of recent isolates of Mycoplasma bovis in Belgium. Vet Rec. 2003;153(14):428-31.

5. Valle M, Schneider M, Galland D, Giboin H, Woehrle F. Pharmacokinetic and pharmacodynamic testing of marbofloxacin administered as a single injection for the treatment of bovine respiratory disease. J Vet Pharmacol Ther. 2012;35(6):519-28.

6. Dossin O, Gruet P, Thomas E. Comparative field evaluation of marbofloxacin tablets in the treatment of feline upper respiratory infections. J Small Anim Pract. 1998;39(6):286-9.

7. Thomas E, Caldow G, Borell D, Davot J. A field comparison of the efficacy and tolerance of marbofloxacin in the treatment of bovine respiratory disease. J Vet Pharmacol Ther. 2001;24(5):353-8.

8. Thomas E, Grandemange E, Pommier P, Wessel-Robert S, Davot J. Field evaluation of efficacy and tolerance of a $2 \%$ marbofloxacin injectable solution for the treatment of respiratory disease in fattening pigs. Vet $\mathrm{Q}$. 2000;22(3):131-5.

9. Shan Q, Liang C, Wang J, Li J, Zeng Z. In vivo activity of cefquinome against Escherichia coli in the thighs of neutropenic mice. Antimicrob Agents Chemother. 2014;58(10):5943-6.

10. Wang J, Shan Q, Ding H, Liang C, Zeng Z. Pharmacodynamics of Cefquinome in a Neutropenic Mouse Thigh Model of Staphylococcus aureus Infection. Antimicrob Agents Chemother. 2014;58(6):3008-12.

11. AliAbadi FS, Lees P. Antibiotic treatment for animals: effect on bacterial population and dosage regimen optimisation. Int J Antimicrob Agents. 2000;14(4):307-13. 
12. Mouton JW, Dudley MN, Cars O, Derendorf H, Drusano GL. Standardization of pharmacokinetic/pharmacodynamic (PK/PD) terminology for anti-infective drugs. Int J Antimicrob Agents. 2002;19(4):355-8.

13. Illambas J, Potter T, Cheng Z, Rycroft A, Fishwick J, Lees P. Pharmacodynamics of marbofloxacin for calf pneumonia pathogens. Res Vet Sci. 2013:94(3):675-81.

14. Potter T, Illambas J, Pelligand L, Rycroft A, Lees P. Pharmacokinetic and pharmacodynamic integration and modelling of marbofloxacin in calves for Mannheimia haemolytica and Pasteurella multocida. Vet J. 2013;195(1):53-8.

15. Ambrose PG, Bhavnani SM, Rubino CM, Louie A, Gumbo T, Forrest A, et al. Pharmacokinetics-pharmacodynamics of antimicrobial therapy: it's not just for mice anymore. Clin Infect Dis. 2007:44(1):79-86.

16. Andes D, Craig WA. Pharmacodynamics of the New Fluoroquinolone Gatifloxacin in Murine Thigh and Lung Infection Models. Antimicrob Agents Chemother. 2002;46(6):1665-70.

17. Higuchi S, Kurosaka Y, Uoyama S, Yoshida K, Chiba M, Ishii C, et al. Anti-multidrug-resistant Acinetobacter baumannii activity of DS-8587: In vitro activity and in vivo efficacy in a murine calf muscle infection model. J Infect Chemother. 2014;20(5):312-6.

18. Andes D, Craig W. In vivo activities of amoxicillin and amoxicillin-clavulanate against Streptococcus pneumoniae: application to breakpoint determinations. Antimicrob Agents Chemother. 1998:42(9):2375-9.

19. Rivera B, Miller SR, Brown EM, Price RE. A novel method for endotracheal intubation of mice and rats used in imaging studies. J Am Assoc Lab Anim Sci. 2005;44(2):52-5.

20. Ferran AA, Kesteman AS, Toutain PL, Bousquet-Melou A. Pharmacokinetic/ pharmacodynamic analysis of the influence of inoculum size on the selection of resistance in Escherichia coli by a quinolone in a mouse thigh bacterial infection model. Antimicrob Agents Chemother. 2009;53(8):3384-90,

21. Kesteman AS, Ferran AA, Perrin-Guyomard A, Laurentie M, Sanders $P$, Toutain PL, et al. Influence of inoculum size and marbofloxacin plasma exposure on the amplification of resistant subpopulations of Klebsiella pneumoniae in a rat lung infection model. Antimicrob Agents Chemother. 2009;53(11):4740-8.

22. Ferran AA, Toutain PL, Bousquet-Melou A. Impact of early versus later fluoroquinolone treatment on the clinical; microbiological and resistance outcomes in a mouse-lung model of Pasteurella multocida infection. Vet Microbiol. 2011;148(2-4):292-7.

23. Abo-el-Sooud K, Goudah A. Influence of Pasteurella multocida infection on the pharmacokinetic behavior of marbofloxacin after intravenous and intramuscular administrations in rabbits. J Vet Pharmacol Ther. 2010;33(1):63-8.

24. Ismail M, El-Kattan Y. Comparative pharmacokinetics of marbofloxacin in healthy and Mannheimia haemolytica infected calves. Res Vet Sci. 2007:82(3):398-404.

25. Dudhani RV, Turnidge JD, Nation RL, Li J. fAUC/MIC is the most predictive pharmacokinetic/pharmacodynamic index of colistin against Acinetobacter baumannii in murine thigh and lung infection models. J Antimicrob Chemother. 2010;65(9):1984-90.

26. Andes D, Craig WA. In vivo pharmacodynamic activity of the glycopeptide dalbavancin. Antimicrob Agents Chemother. 2007;51(5):1633-42.

\section{Submit your next manuscript to BioMed Central and we will help you at every step:}

- We accept pre-submission inquiries

- Our selector tool helps you to find the most relevant journal

- We provide round the clock customer support

- Convenient online submission

- Thorough peer review

- Inclusion in PubMed and all major indexing services

- Maximum visibility for your research 